\title{
Frequent loss of PDCD4 expression in human glioma: Possible role in the tumorigenesis of glioma
}

\author{
FEI GAO ${ }^{1 *}$, PIN ZHANG $^{1 *}$, CHUIXIAN ZHOU ${ }^{2},{\text { JIANFENG } \text { LI }^{3} \text {, QUN WANG }}^{1}$, \\ FALIANG ZHU ${ }^{1}$, CHUNHONG MA ${ }^{1}$, WENSHENG SUN ${ }^{1}$ and LINING ZHANG ${ }^{1}$ \\ ${ }^{1}$ Institute of Immunology, School of Medicine, and ${ }^{2}$ Department of NeuroSurgery, QiLu Hospital, \\ Shangdong University; ${ }^{3}$ Central Laboratory, Shandong Provincial Hospital, Shandong, Jinan 250021, P.R. China
}

Received August 7, 2006; Accepted October 30, 2006

\begin{abstract}
Programmed cell death 4 (PDCD4) was recently identified as a novel tumor suppressor gene. The loss of PDCD4 expression was found in several types of human cancer cell lines. To date, however, the status of PDCD4 expression in human glioma tissue is not known. In the present study, the expression of PDCD4 in 30 glioma samples was determined at both mRNA and protein levels by means of RT-PCR, Western blotting, and immunohistochemistry. Herein, we demonstrate, for the first time, that $47 \%$ (14/30) of glioma samples lost the expression of PDCD4 mRNA, and $77 \%$ (23/30) of glioma samples lacked the PDCD4 protein expression, whereas adjacent normal glial tissues expressed high levels of PDCD4 mRNA and protein. Furthermore, the loss of PDCD4 expression does not significantly correlate with the pathological and clinical features of the glioma. Our new data suggest that the loss of PDCD4 expression is a frequent event in human glioma and may partially contribute to the development of the tumor.
\end{abstract}

\section{Introduction}

Human gliomas are the most common tumor that arises in the central nervous system. As nearly half of gliomas are histologically malignant, therapy of gliomas is one of the most formidable challenges in human malignancies. Over the past two decades, the overall survival of patients suffering from the disease has been improved little, despite therapeutic strategies to employ surgery in combination with radiation and chemotherapy $(1,2)$. Therefore, studies of the molecular

Correspondence to: Dr Lining Zhang, Institute of Immunology, School of Medicine, Shandong University, 44 Wenhua Xilu, Shandong, Jinan 250012, P.R. China

E-mail: zhang_lining@hotmail.com

${ }^{*}$ Contributed equally

Key words: programmed cell death 4, suppressor gene, glioma, gene expression biology of the tumor are key issues to getting insight into the mechanisms underlying the pathogenesis of glioma and, in turn, leading to effective therapeutics finally. In recent years, there has been considerable progress in understanding the genetic alterations that cause the initiation and progression of gliomas (3). It is now known that malignant gliomas arise from a number of well-characterized genetic alterations and activations of oncogenes and inactivation of tumor suppressor genes (1). Programmed cell death 4, PDCD4, was recently identified as a novel tumor suppressor gene. To date, however, its role in human glioma is not clear.

PDCD4 was first cloned as a gene whose elevated expression is associated with the occurrences of apoptosis in mouse cell lines (4). Subsequently, certain other different mammalian homologues of PDCD4 were identified. So, PDCD4 represents a new pre-apoptotic gene. It is generally accepted that cancer is a disease with deregulated cell proliferation, abnormal differentiation and disturbed apoptosis (5). Thus, it is conceivably inferred that PDCD4 may exert a crucial role in the mechanisms underlying carcinogenesis. Indeed, the following studies demonstrated that PDCD4 was able to inhibit tumor promoter-induced transformation in the mouse JB6 model system (6-8), thereby confirming that PDCD4 acts as a novel tumor suppressor gene. Furthermore, previous studies have shown that PDCD4 exerted its antitumor roles via regulating signal transduction pathways $(9,10)$.

Human PDCD4 is first cloned from a human glioma library, which is highly homologous to the mouse PDCD4 $(11,12)$. It is expressed ubiquitously in human normal tissues, whereas loss of its expression is found in several types of human cancer cell lines (13), and in primary lung cancer (14) and in primary pancreatic cancer (15). However, the status of PDCD4 expression in human primary gliomas is unknown. In the present study, the expression of PDCD4 in 30 primary gliomas was determined at both mRNA and protein levels by means of RT-PCR, Western blotting and immunohistochemistry.

\section{Materials and methods}

Carcinoma specimens. Glioma specimens were obtained from 30 patients aged between 40 and 60 years (mean 50 years) who underwent operations at the Department of Neurosurgery in QiLu Hospital of Shandong University from March 2005 
to March 2006. No patient had received adjuvant immunosuppressive treatment including radiotherapy or chemotherapy prior to surgery in order to eliminate the variable from affecting gene expression. With written informed consent obtained from all patients, the specimens were immediately frozen in liquid nitrogen after surgical tissue removal, and then kept at $-80^{\circ} \mathrm{C}$. The three normal glial tissues were all acquired from tumor adjacent tissue. The U251 cell line from glioma was purchased from Shanghai Cell Bank of Chinese Academy of Sciences. This study was completely in compliance with national legislation and the ethical principles of the Chinese Medical Association. The pathological analysis was according to World Health Organization (WHO) criteria.

Antibodies and reagents. Rabbit anti-human PDCD4 polyclonal antibody was presented by Dr Nancy Culburn from the National Institutes of Health, USA. Peroxidase-conjugated goat anti-rabbit IgG was obtained from KPL Co. (Maryland, USA). TRIzol ${ }^{\circledR}$ was purchased from Sangon Biotech Co., Ltd (Shanghai, P.R. China); a Reverse-Transcribe kit was purchased from Promega Co. (Madison, USA); and PCR MIX was obtained from Tiangen reagent (Beijing, P.R. China).

$R T$-PCR. Total RNAs were extracted from 30 glioma specimens, 3 normal tissue specimens and glioma cell line (U251) cells using a modified TRIzol ${ }^{\circledR}$ one-step extraction method $(16,17)$. CDNA was reversely transcribed by the Reverse-Transcribe kit according to the manufacturer's instructions. The reaction was first performed at $70^{\circ} \mathrm{C}$ for $10 \mathrm{~min}$, and then at $42^{\circ} \mathrm{C}$ for $1 \mathrm{~h}$, followed by $95-99^{\circ} \mathrm{C}$ for 5 min to stop the reaction. PCR was performed using PDCD4 specific primers (sense 5'-CCA, AAG, AAA, GGT, GGT, GCA-3', and antisense 5'-TGA, GGT, ACT, TCC, AGT, TCC-3'). The PCR reaction mix for each sample included $12.5 \mu 1$ of $2 \mathrm{X}$ Master mix (0.1 U TaqDNA polymerase, $500 \mu \mathrm{M}$ dNTP, $3 \mathrm{mM} \mathrm{MgCl}$, $100 \mathrm{mM} \mathrm{KCl,} 20 \mathrm{mM}$ Tris$\mathrm{HCl}), 0.5 \mu \mathrm{l}$ of forward primer $(5 \mu \mathrm{M}), 0.5 \mu \mathrm{l}$ of reverse primer $(5 \mu \mathrm{M}), 1 \mu \mathrm{l}$ of the DNA sample, and $10.5 \mu 1$ of $\mathrm{H}_{2} \mathrm{O}$. The sample was denatured at $94^{\circ} \mathrm{C}$ for $2 \mathrm{~min}$, followed by 35 cycles of $95^{\circ} \mathrm{C}$ for $1 \mathrm{~min} 30 \mathrm{sec}, 66^{\circ} \mathrm{C}$ for $1 \mathrm{~min} 30 \mathrm{sec}$, and $72^{\circ} \mathrm{C}$ for $1 \mathrm{~min} 30 \mathrm{sec}$ with an extension cycle at $72^{\circ} \mathrm{C}$ for $5 \mathrm{~min}$. For each PCR reaction, pure water (no DNA template) was used as a reagent negative control. Human B-actin was amplified as an internal control from parallel samples. All PCR products were electrophoresed on a $1.5 \%$ agarose gel. The RT-PCR was performed at least twice in independent experiments.

SDS-PAGE and Western blotting. The proteins were extracted from tissue samples using a modified TRIzol ${ }^{\circledR}$ one-step extraction method $(16,17)$. In brief, tissues were homogenized and then lysed by TRIzol. After centrifution, upper phase containing RNA was removed for RNA extraction, and then interphase and organic phase were collected for protein extraction. The proteins were precipitated by acetone. After washing three times, the protein extraction was dissolved in loading buffer ( $1 \mathrm{mM}$ Tris $\cdot \mathrm{Cl}, 3 \% \mathrm{SDS}, 60 \%$ glycerol, $75 \mathrm{mM}$ DTT). Of each sample $25 \mu \mathrm{g}$ was analysed by SDS-PAGE on a $12 \%$ gel and then was transferred to the nitrocellulose membrane. After blocking with $5 \%$ skim milk in TBST
A.

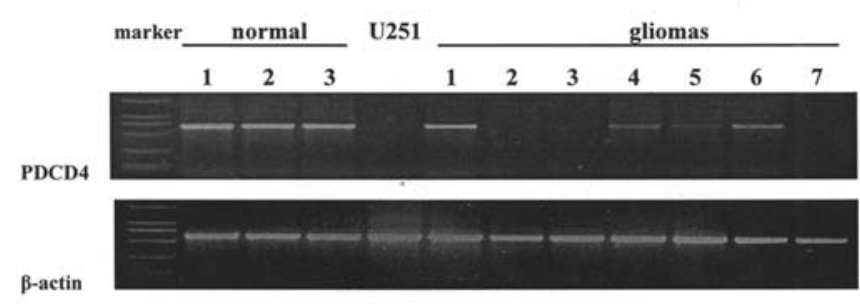

B.

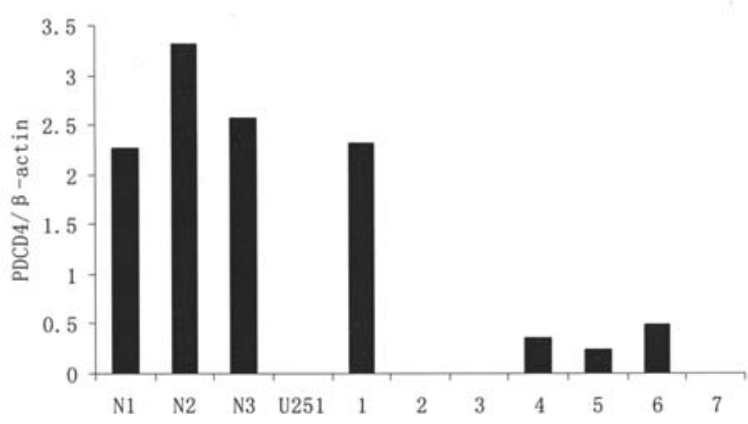

Figure 1. Expression of PDCD4 mRNA in gliomas detected by RT-PCR. (A) Electrophoresis of PCR products on agarose gel. Amplified DNA product was $673 \mathrm{bp}$ in length and $\beta$-actin product was $613 \mathrm{bp}$ in length. The marker comprises of $2000,1000,750,500,250$, and $100 \mathrm{bp}$, from upper to lower. (B) The OD value of the PDCD4 normalized to $ß$-actin. A high level of PDCD4 mRNA expression was detected in all of three normal brain tissues adjacent to tumor (normal 1,2,3), while no PDCD4 expression was observed in the glioma cell line (U251) or in gliomas $(2,3,7)$. Otherwise, there was reduced PDCD4 expression in gliomas $(4,5,6)$.

containing $0.1 \%$ Tween-20 (Sigma-Aldrich), the membrane was incubated with rabbit anti-human PDCD4 antibody (1:10000) or human $\beta$-actin antibody $(1: 1000)$ at $4^{\circ} \mathrm{C}$ overnight, washed three times, and incubated with peroxidase-conjugated goat anti-rabbit IgG. Following washing, immunoreactive bands were visualized using the enhanced chemiluminescence method according to the manufacturer's instructions (ECL, Amersham Biosciences, UK). Equal concentrations of each protein were determined by Bradford analysis and Western blotting was performed at least twice in independent experiments.

Immunohistochemistry. A 4- to 6- $\mu \mathrm{m}$ section was prepared from freezed glioma tissues and normal brain tissues adjacent to tumor at $-80^{\circ} \mathrm{C}$ using the freezing microtome and used for H\&E staining or immunostaining. After being fixed by cold acetone, the slides were washed 3 times with PBS, blocked for endogenous peroxidase activity, preincubated with goat serum, and then incubated with anti-PDCD4 antibody (1:200) for $1 \mathrm{~h}$ at room temperature in a humid chamber. The sections were washed three times for $3 \mathrm{~min}$ at room temperature with PBS and then visualized with Rabbit IgG avidin-biotin peroxidase complex kit and DAB peroxidase substrate kit (Maixin Co., Fuzhou, P.R. China). The nuclei were counterstained with hematoxylin. Negative controls for the specificity of immunohistochemical reactions were performed by replacing the primary antibody with PBS. All of the slides were independently analyzed by two pathologists. 
Table I. Analysis of PDCD4 expression in gliomas.

\begin{tabular}{|c|c|c|c|c|c|}
\hline \multirow[t]{2}{*}{ No. } & \multirow[t]{2}{*}{ RNA } & \multicolumn{2}{|c|}{ Protein } & \multirow[t]{2}{*}{ Grade } & \multirow[t]{2}{*}{ Classification } \\
\hline & & WB & $\mathrm{IH}$ & & \\
\hline 1 & ++++ & + & + & GIV & Glioblastoma \\
\hline 2 & - & - & - & GIV & Anaplastic astrocytoma \\
\hline 3 & - & - & - & GIV & Medulloblastoma \\
\hline 4 & + & + & + & GIV & Anaplastic astrocytoma \\
\hline 5 & + & - & - & GII-III & Astrocytic tumours \\
\hline 6 & + & + & + & GII-III & Fibrillary astrocytoma \\
\hline 7 & - & - & - & GII-III & Astrocytic tumours \\
\hline 9 & ++++ & - & - & GII-III & Oligodendroglioma \\
\hline 10 & - & - & - & GIV & Glioblastoma \\
\hline 11 & + & - & - & GII-III & Astrocytic tumours \\
\hline 12 & ++++ & - & - & GIV & Glioblastoma \\
\hline 13 & ++ & - & - & GIV & Anaplastic astrocytoma \\
\hline 14 & + & - & - & GII-III & Anaplastic oligodendroglioma \\
\hline 15 & + & - & - & GIV & Anaplastic astrocytoma \\
\hline 16 & - & - & - & GIV & Anaplastic astrocytoma \\
\hline 17 & + & - & - & GIV & Glioblastoma \\
\hline 18 & - & - & - & GII-III & Anaplastic oligodendroglioma \\
\hline 19 & + & - & - & GI-II & Astrocytic tumours \\
\hline 20 & - & - & - & GI-II & Central neurocytoma \\
\hline 21 & +++ & + & + & GIV & Anaplastic astrocytoma \\
\hline 22 & - & - & - & GIV & Glioblastoma \\
\hline 23 & ++ & + & + & GII-III & Astrocytic tumours \\
\hline 24 & + & + & + & GIV & Glioblastoma \\
\hline 25 & + & + & + & GII-III & Anaplastic oligodendroglioma \\
\hline 26 & - & - & - & GII-III & Astrocytic tumours \\
\hline 27 & - & - & - & GII-III & Oligodendroglioma \\
\hline 28 & - & - & - & GIV & Glioblastoma \\
\hline 29 & - & - & - & GII-III & Astrocytic tumours \\
\hline 30 & - & - & - & GIV & Glioblastoma \\
\hline 31 & - & - & - & GII-III & Astrocytic tumours \\
\hline
\end{tabular}

The pathological analysis was according to World Health Organization (WHO) criteria (1999). The level of PDCD4 mRNA levels were analysed by semi-quantitative RT-PCR according to the OD value of PDCD4 mRNA expression normalized to ß-actin: -, no detection; +, 0.01 to $0.49 ;++, 0.5$ to $0.99 ;+++, 1.0$ to $1.99 ;++++, \geq 2.00$. Expression of PDCD4 protein was detected by Western blotting (WB) and immunohistochemistry $(\mathrm{IH})$ : +, expression; -, loss.

Statistical analysis. The $\chi^{2}$ test was used to analyse the correlation of expression of PDCD4 protein with pathological characters. p-values $<0.05$ were considered statistically significant. All calculations were performed through the SPSS statistical software package.

\section{Results}

Lacking or decreased expression of PDCD4 mRNA in gliomas. To study the role of PDCD4 in the gliomas, we firstly examined the PDCD4 expression at RNA level by semiquantitative RT-PCR according to the OD value of PDCD4 mRNA expression normalized to ß-actin: -, no detection; +,
0.01 to $0.49 ;++, 0.5$ to $0.99 ;+++, 1.0$ to $1.99 ;++++, \geq 2.00$. As illustrated in Fig. 1, all of three normal brain tissues adjacent to the tumor lesion expressed a high level of PDCD4 mRNA, whereas most of the gliomas expressed reduced or lacked PDCD4 mRNA. In 30 glioma specimens, 14 (47\%) lost PDCD4 mRNA expression (Table I). In the remaining 16 glioma samples, 12 (40\% of 30) appeared differently reduced in PDCD4 mRNA expression compared with three normal tissue controls. For example, PDCD4s were lost in the glioma samples 2, 3, and 7 and distinctly reduced in the glioma samples 4, 5, and 6; while glioma sample 1 was almost identical with the normal tissue control as shown in Fig. 1. $\mathrm{U} 251$ is a cell line originated from glioma. It has been reported 


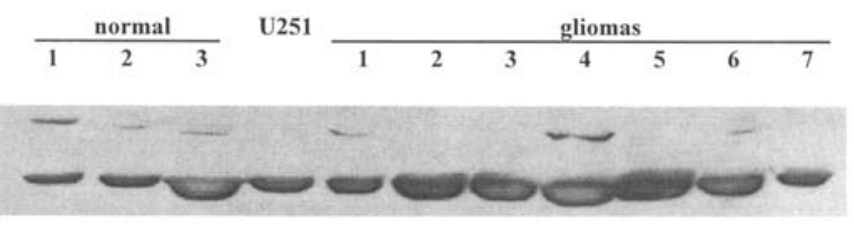

Figure 2. Western blot analysis of PDCD4 protein expression in glioma. The proteins extracted from tissues or cell lines of each sample were analysed by SDS-PAGE on a $12 \%$ gel and then was transferred to the nitrocellulose membrane. The PDCD4 protein expression was detected by anti-PDCD4 antibody. The normal brain tissues (normal 1,2,3) expressed PDCD4 protein while the glioma cell line (U251) and some gliomas (glioma 2, 3, 5,7) lacked PDCD4 expression.

that the cell line almost loses expression of PDCD4 mRNA (14). Our result was identical with that of the previous report.

High frequent loss of PDCD4 protein expression in gliomas. Based on the above studies, we further examined the expression of PDCD4 protein by Western blotting and immunohistochemistry. The data from Western blot experiment showed that the loss of PDCD4 proteins was more than that of PDCD4 mRNA (Table I). In 30 cases of the gliomas, $23(77 \%)$ exhibited no relevant PDCD4 bands and the other 6 showed weak PDCD4 bands, compared with normal brain tissues adjacent to tumor, which showed strong PDCD4 expression (Fig. 2). Only samples 1, 4, and 6 had slight expression. While other samples, e.g. samples 2, 3, 5, and 7, were lost in the protein level. Noteworthily, some gliomas such as sample 5 expressed PDCD4 mRNA but not PDCD4 protein. These suggested that loss of PDCD4 expression in certain gliomas might occur after mRNA transcription.

Immunohistochemistry analysis showed that the PDCD4 protein expression in the tumor tissue sections were similar to those from Western blot analysis (Table I). The tumor adjacent tissue such as case 24 showed very strong PDCD4 expression (Fig. 3A), while its paired tumor tissue exhibited decreased PDCD4 staining (Fig. 3B). In certain gliomas, such as case 29 , there was almost no relevant PDCD4 staining (Fig. 3C). In addition, Fig. 3 showed that the positive PDCD4 staining localized in cytoplasm.

The loss of PDCD4 in gliomas had no significant relationships with tumor grade or histological type. To explore the significance of no PDCD4 protein in gliomas, we further analysed the relationship between loss of PDCD4 protein and clinicopathological parameters. As expected, there was no significant correlation of lack of PDCD4 expression with sex, age, and tumor size (data not shown). Unexpectedly there was also no significant relationship between loss of PDCD4 expression and tumor grade or histological type (Fig. 4).

\section{Discussion}

Previous study of mammalian cell lines has confirmed that PDCD4 acts as a novel tumor suppressor gene (12,18-24). Up to now, however, the genetic variability of PDCD4 in human primary tumor tissues was only limited in lung cancer and pancreatic cancer (15). The result analyzed by Chen et al demonstrated that $83 \%$ of lung cancers lacked the expression of PDCD4 proteins and found that loss of PDCD4 expression
A.

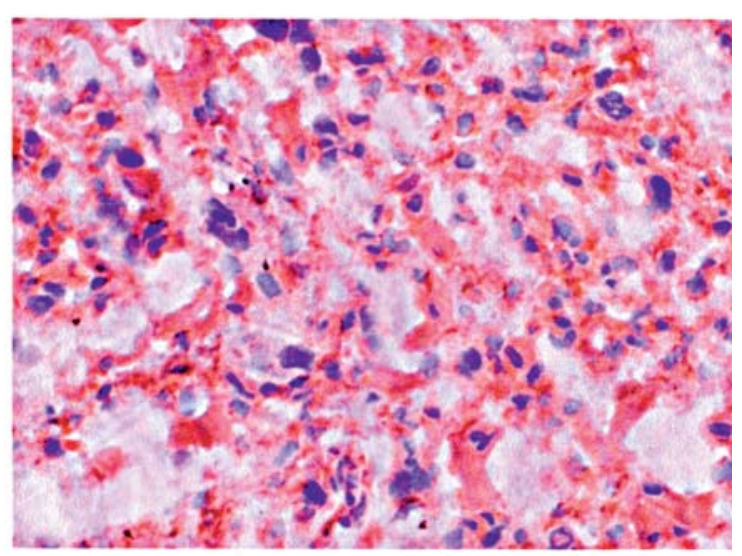

B.

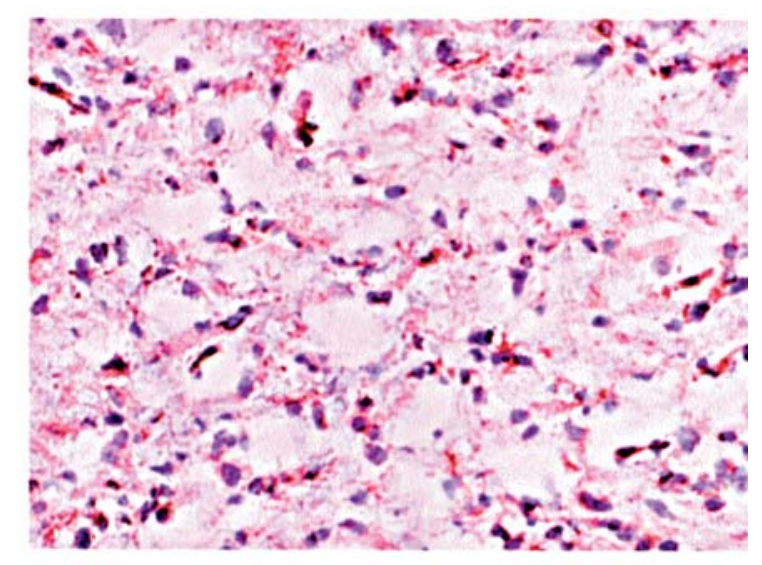

C.

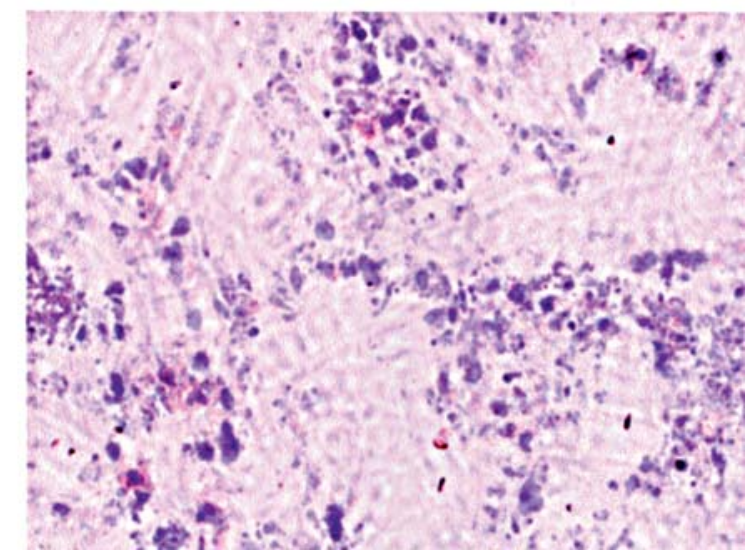

Figure 3. Immunohistochemistry analysis of PDCD4 protein expression in glioma. The products of PDCD4 expression (brown) located in cytoplasm. The tumor adjacent tissue control (A) showed very strong PDCD4 expression (brown staining in cytoplasm). The tumor tissues (B) exhibited decreased PDCD4 or lacked PDCD4 expression (C).

in human lung cancer samples correlated with tumor progression and prognosis (14). In the present study, we clearly demonstrate, for the first time, that high frequent loss of PDCD4 expression exists in primary gliomas, of which $47 \%$ (14/30) lost the expression of PDCD4 mRNA, and 77\% (23/30) lacked the PDCD4 protein expression. However, the loss of 
A.

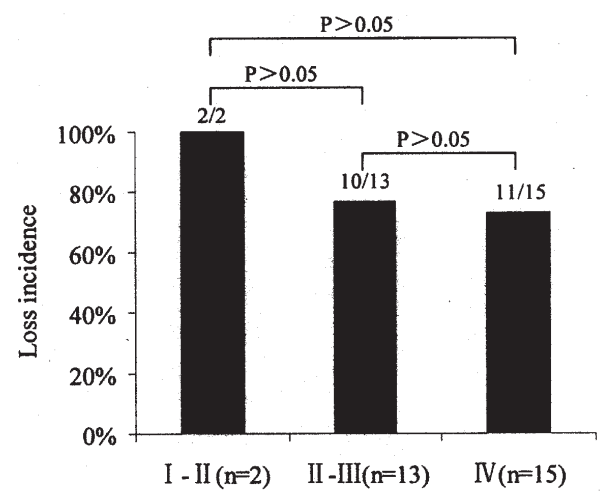

B.

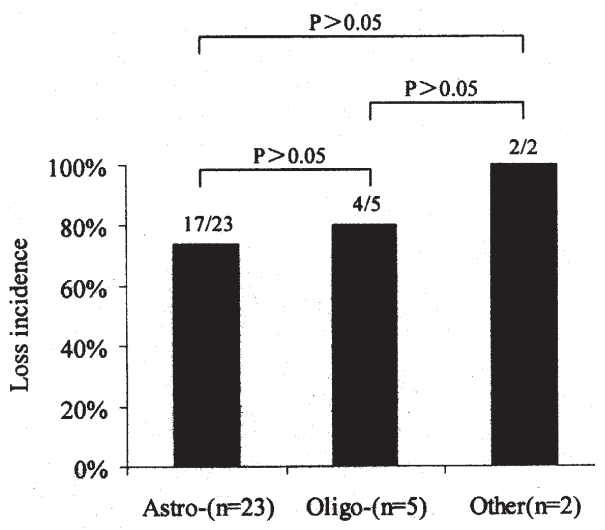

Figure 4. The correlation of loss of PDCD4 protein with pathological grade or histological type. The loss of PDCD4 protein had no significant correlation with pathological grade (A) and histological type (B).

PDCD4 expression in gliomas had no significant relationship with tumor grade, histological type or prognosis.

At present, the molecular basis for the PDCD4 expression pattern is unclear. In this study, certain samples lost PDCD4 expression in the mRNA level, whereas other samples lost it in the protein level. The explanation for the loss of expression might be tissue-specific or related to mutation of the initiator or to certain genes that control PDCD4 expression $(25,26)$. In fact, the inactivation of the tumor suppressor gene may not only happen in the transcription level through gene mutation but also in the protein level for the change of certain modulate genes as a result of reduced gene expression. Our results show that PDCD4 expression is higher in the normal tissue, i.e. tumor adjacent tissue, than the tumor tissue for the paired tumor sample by immunohistochemistry. We presume that the alteration may be related with the initiation of the tumor by inactivation of the suppressor gene. In addition, our results indicate that loss or absence of PDCD4 expression may play a crucial role in the pathogenesis of glioma, maybe via downregulation of apoptosis.

Our data showed that loss of PDCD4 expression had no significant association with tumor grade or histological type. So the significance of high frequent loss of PDCD4 expression in gliomas is unclear. Interestingly, Jansen et al found that the PDCD4 expression was associated with drug sensitivity (13). It has been observed that most gliomas are not sensitive to drugs. Maybe the high frequent loss of PDCD4 expression in gliomas relates to the low drug sensitivity of the tumor.
Therapeutic strategies to up-regulate PDCD4 expression in gliomas may offer a promising treatment for the patients. However, this needs to be confirmed in the future.

In conclusion, our new results suggest that loss or absence of PDCD4 expression may be a key factor in the tumorigenesis of glioma. However, the precise mechanism by which PDCD4 expression affects the tumorigenesis of glioma needs to be investigated further in a large set of patient samples.

\section{Acknowledgements}

We particularly thank Dr NH Colburn from the National Institutes of Health, USA, for kindly presenting us with the anti-PDCD4 antibody and we are grateful to Dr Youhai Chen from Department of Pathology and Laboratory Medicine, University of Pennsylvania School of Medicine, USA, for his valuable suggestion and kind help with our study. This work was supported by grants from the Natural Science Foundation of China (No. 30371352) and the National Basic Research Program (No. 2006CB503803).

\section{References}

1. Bansal K, Liang ML and Rutka JT: Molecular biology of human gliomas. Technol Cancer Res Treat 5: 185-194, 2006.

2. Nakabayashi H, Hara M and Shimuzu K: Clinicopathologic significance of cystatin $\mathrm{C}$ expression in gliomas. Hum Pathol 36: 1008-1015, 2005.

3. Perunovic B, Athanasiou A, Quilty RD, Gorgoulis VG, Kittas C and Love S: Expression of mos in astrocytic tumors and its potential role in neoplastic progression. Hum Pathol 33: 703-707, 2002.

4. Shibahara K, Asano M, Ishida Y, Aoki T, Koike T and Honjo T: Isolation of a novel mouse gene MA-3 that is induced upon programmed cell death. Gene 166: 297-301, 1995.

5. McDonnell TJ, Deane N, Platt FM, Nunez G, Jaeger U, McKearn JP and Korsmeyer SJ: bcl-2-immunoglobulin transgenic mice demonstrate extended B cell survival and follicular lymphoproliferation. Cell 57: 79-88, 1989.

6. Cmarik JL, Min H, Hegamyer G, Zhan S, Kulesz-Martin M, Yoshinaga H, Matsuhashi S and Colburn NH: Differentially expressed protein PDCD4 inhibits tumor promoter-induced neoplastic transformation. Proc Natl Acad Sci USA 96: 14037-14042, 1999.

7. Dhar A, Young MR and Colburn NH: The role of AP-1, NFkappaB and ROS/NOS in skin carcinogenesis: the JB6 model is predictive. Mol Cell Biochem 234-235: 185-193, 2002.

8. Yang HS, Knies JL, Stark C and Colburn NH: PDCD4 suppresses tumor phenotype in JB6 cells by inhibiting AP-1 transactivation. Oncogene 22: 3712-3720, 2003.

9. Bitomsky N, Bohm M and Klempnauer KH: Transformation suppressor protein PDCD4 interferes with JNK-mediated phosphorylation of c-Jun and recruitment of the coactivator p300 by c-Jun. Oncogene 23: 7484-7493, 2004.

10. Yang HS, Matthews CP, Clair T, Wang Q, Baker AR, Li CC, Tan TH and Colburn NH: Tumorigenesis suppressor PDCD4 down-regulates mitogen-activated protein kinase kinase kinase kinase 1 expression to suppress colon carcinoma cell invasion. Mol Cell Biol 26: 1297-1306, 2006.

11. Matsuhashi S, Yoshinaga H, Yatsuki H, Tsugita A and Hori K: Isolation of a novel gene from a human cell line with Pr-28 Mab which recognizes a nuclear antigen involved in the cell cycle. Res Commun Biochem Cell Mol Biol 1: 109-120, 1997.

12. Yang HS, Jansen AP, Komar AA, Zheng X, Merrick WC, Costes S, Lockett SJ, Sonenberg N and Colburn NH: The transformation suppressor Pdcd4 is a novel eukaryotic translation initiation factor 4A binding protein that inhibits translation. Mol Cell Biol 23: 26-37, 2003.

13. Jansen AP, Camalier CE, Stark C and Colburn NH: Characterization of programmed cell death 4 in multiple human cancers reveals a novel enhancer of drug sensitivity. Mol Cancer Ther 3: 103-110, 2004. 
14. Chen Y, Knosel T, Kristiansen G, Pietas A, Garber ME, Matsuhashi S, Ozaki I and Petersen I: Loss of PDCD4 expression in human lung cancer correlates with tumour progression and prognosis. J Pathol 200: 640-646, 2003.

15. Ma G, Guo KJ, Zhang H, Ozaki I, Matsuhashi S, Zheng XY and Dong M: Expression of programmed cell death 4 and its clinicopathological significance in human pancreatic cancer. Zhongguo Yi Xue Ke Xue Yuan Xue Bao 27: 597-600, 2005.

16. Chadderton T, Wilson C, Bewick M and Gluck S: Evaluation of three rapid RNA extraction reagents: relevance for use in RTPCR's and measurement of low level gene expression in clinical samples. Cell Mol Biol (Noisy-le-grand) 43: 1227-1234, 1997.

17. Culley DE, Kovacik WP Jr, Brockman FJ and Zhang W: Optimization of RNA isolation from the archaebacterium Methanosarcina barkeri and validation for oligonucleotide microarray analysis. J Microbiol Methods (in press).

18. Afonja O, Juste D, Das S, Matsuhashi S and Samuels HH: Induction of PDCD4 tumor suppressor gene expression by RAR agonists, antiestrogen and HER-2/neu antagonist in breast cancer cells. Evidence for a role in apoptosis. Oncogene 23: 8135-8145, 2004.

19. Goke A, Goke R, Knolle A, Trusheim H, Schmidt H, Wilmen A, Carmody R, Goke B and Chen YH: DUG is a novel homologue of translation initiation factor $4 \mathrm{G}$ that binds eIF4A. Biochem Biophys Res Commun 297: 78-82, 2002.

20. Goke R, Gregel C, Goke A, Arnold R, Schmidt H and Lankat-Buttgereit B: Programmed cell death protein 4 (PDCD4) acts as a tumor suppressor in neuroendocrine tumor cells. Ann NY Acad Sci 1014: 220-221, 2004.
21. Jansen AP, Camalier CE and Colburn NH: Epidermal expression of the translation inhibitor programmed cell death 4 suppresses tumorigenesis. Cancer Res 65: 6034-6041, 2005.

22. Lankat-Buttgereit B, Gregel C, Knolle A, Hasilik A, Arnold R and Goke R: PDCD4 inhibits growth of tumor cells by suppression of carbonic anhydrase type II. Mol Cell Endocrinol 214: 149-153, 2004.

23. Stalberg P, Lopez-Egido JR, Wang S, Gobl A, Oberg K and Skogseid B: Differentially expressed cDNAs in PLCbeta3-induced tumor suppression in a human endocrine pancreatic tumor cell line: activation of the human mismatch repair protein 3 gene. Biochem Biophys Res Commun 281: 227-231, 2001.

24. Yoshinaga H, Matsuhashi S, Fujiyama C and Masaki Z: Novel human PDCD4 (H731) gene expression in proliferative cells is expressed in the small duct epithelial cells of the breast as revealed by an anti-H731 antibody. Int Pathol 49: 1067-1077, 1997.

25. Azzoni L, Zatsepina O, Abebe B, Bennett IM, Kanakaraj P and Perussia B: Differential transcriptional regulation of CD161 and a novel gene, 197/15a, by IL-2, IL-15, and IL-12 in NK and T cells. J Immunol 161: 3493-3500, 1998.

26. Schlichter U, Burk O, Worpenberg S and Klempnauer KH: The chicken PDCD4 is regulated by v-Myb. Oncogene 20: 231-239, 2001 . 